\title{
Restrictive deterrence: Avoiding arrest in rural methamphetamine markets
}

Julie Yingling

Lycoming College

Campus Post Office Box 2

Williamsport, Pennsylvania 17701

Contact information: yingling@1ycoming.edu; 570-321-4202

\begin{abstract}
A component of restrictive deterrence, arrest avoidance is the notion that offenders employ specific strategies to evade detection. Although research focuses on the tactics drug dealers use to avoid law enforcement detection in crack, heroin, and marijuana markets in urban locations, no studies explore these techniques in rural settings or methamphetamine markets. Based on interviews with 52 men and women involved in methamphetamine markets, this article explores the arrest avoidance strategies used during ingredient acquisition, manufacturing, and distribution of methamphetamine. This study also expands the restrictive deterrence literature by asking each participant if they experienced a methamphetamine related arrest and how their arrest avoidance strategies related to their arrests. When participants were arrested, they revealed that they were sometimes not using any strategies or that some unique situation (i.e. getting set up by a friend) was the reason for their arrest rather than ineffective avoidance tactics.
\end{abstract}

Keywords: restrictive deterrence, methamphetamines, drug markets, rural drug production and trafficking 


\section{Introduction}

Restrictive deterrence is a useful theoretical approach to examine how offenders avoid police detection and apprehension (Gibbs, 1975). By avoiding law enforcement or the suspicions of law enforcement, offenders are able to operate for longer periods of time. Restrictive deterrence within drugs markets is well tested, although almost exclusively in urban locations and in crack and heroin markets (Jacobs \& Miller, 1998; Jacobs, 1996a; 1996b; Johnson \& Natarajan, 1995; Molloney et al., 2015; VanNostrand \& Tewksbury, 1999). No restrictive deterrence strategies examine arrest avoidance strategies in rural or methamphetamine markets. Further, only one study examines the effectiveness of drug offenders who use or change their arrest avoidance strategies (Gallupe et al., 2011). Gallupe et al. (2011) quantitative study found that offenders who changed their strategies after an arrest increased their likelihood of re-arrest, likely because offenders were placing themselves into unfamiliar markets and situations (Gallupe et al., 2011). No qualitative research examines drug offenders' arrest avoidance strategies and their thoughts on the effectiveness of their tactics.

\section{Theoretical background}

The threat of punishment is not always enough to deter offenders from crime (Gibbs, 1975). Rather than desisting from crime, criminals simply alter their criminal behavior to prevent arrest. Restrictive deterrence "refers to a reduction in the frequency of offenses, including any strategies or tactics employed by individuals to evade detection, identification, or apprehension that have the effect of reducing the frequency of offenses" (Gibbs, 1975, p.33). Jacobs (1996b) further refined restrictive deterrence to delineate probabilistic and particularistic types. Probabilistic restrictive deterrence is a "reduction in offense frequencies based on a "law of averages' mentality" (Jacobs, 1996b, p. 376). Particularistic restrictive deterrence is "a reduction in offense frequencies based on tactical skills used by offenders to make their crimes less detectable and reducing their chances for apprehension" (Jacobs, 1996b, p.376). This study focuses on particularistic restrictive deterrence and the specific strategies methamphetamine market-involved individuals use in rural communities to avoid detection by police and reduce their odds of arrest.

The most commonly used tactics to avoid law enforcement detection in drug markets revolve around selling drugs. Dealers change their cell phone numbers frequently to limit customers and avoid police (Fader, 2016; Jacobs \& Miller, 1998). When selling drugs, dealers frequently stay covert by only selling to people they know (Jacobs, 1993; Jacobs, 1996a; Jacques \& Allen, 2014; Jacques \& Reynald, 2012; Johnson \& Natarajan, 1995; Morgan \& Joe, 1996; VanNostrand \& Tewksbury, 1999; Worden et al., 1994). Dealers are suspicious of new customers because they could be undercover law enforcement (Jacques \& Allen, 2014; Jacques \& Reynald, 2012). Further, buyers bringing others with them (VanNostrand \& Tewksbury, 1999) or buyers suddenly introducing unknown others to the dealer (Jacobs, 1993) is viewed as a possible set up. Dealers are also selective about their regular customers (Dickinson \& Wright, 
2015; Jacques \& Allen, 2014; VanNostrand \& Tewksbury, 1999). In a study of twenty (mostly crack) dealers participating in a drug court diversion program, dealers avoided the drug addicted users in their communities, preferring middle- and upper-class clients who were not viewed as problematic addicts due to their status, class, and seemingly recreational use. Dealers viewed addicts as dishonest and untrustworthy and did not want to deal with addicts' lack of cash and requests for credit or trades (VanNostrand \& Tewksbury, 1999). Dealers also avoided selling to users who had been arrested fearing that the busted user could be working as a confidential informant for the police (Dickinson \& Wright, 2015). Dickinson and Wright (2015) also found that dealers simply avoided buyers who were acting 'sketchy.' Citing mistrust, dealers fear erratic or careless buyers will result in police attention. These strategies around who dealers sell to are nearly all based in large cities with open air markets where law enforcement officers are frequently conducting undercover buys. This arrest avoidance strategy is documented in a study of suburban drug sellers (Jacques \& Allen, 2014). However, it is unknown if these strategies exist in rural markets.

Dealers also choose their selling location carefully (Fader, 2016; Jacobs, 1996b; Johnson \& Natarajan, 1995; VanNostrand \& Tewksbury, 1999; Worden et al., 1994). Dealers avoided areas where police frequently patrol (Johnson \& Natarajan, 1995; VanNostrand \& Tewksbury, 1999). Furthermore, dealers choose locations with good vantage points where they can look for anything suspicious and keep an eye on the people hanging around (Jacobs, 1996b). Some dealers prefer to sell drugs inside, rather than exposed on the street (Fader, 2016; Johnson \& Natarajan, 1995; Sviridoff \& Hillsman, 1994; VanNostrand \& Tewksbury, 1999). Dealers appreciate that sales from their homes cannot be observed by police. Dealers also make sales in stores to disguise the transaction as a simple shopping trip. Before making the transaction, VanNostrand \& Tewksbury (1999) found that some dealers would move buyers into alleys or other outdoor areas with low visibility under the assumption that undercover police would never go to a second location or allow themselves to be out of sight of other watching officers. The literature on selecting locations to avoid arrest is based exclusively on urban research (Jacobs, 1996b; Johnson \& Natarajan, 1995; Sviridoff \& Hillsman, 1994; VanNostrand \& Tewksbury, 1999; Worden et al., 1994). Literature does not account for where rural drug markets, particularly methamphetamine, operate, and how those locations prevent police detection.

Dealers employ several tactics to reduce police detection while making a drug sale in an open-air market. First, dealers use sleight of hand tricks to disguise the transaction as a high-five or hug (Jacobs, 1996b). Jacobs (1996b) found that dealers are quite adept at hiding small amounts of drugs on their person that would go unnoticed if frisked by police. Hiding places include in mouths, baseball caps, socks, hair, rectums, and armpits (Jacobs, 1996b). Dealers also stash their drugs and cash in a safe, secure location so they are not carrying their entire supply on their person in the event of an arrest (Bourgois, 1996; Fader, 2016; Jacobs \& Miller, 1998; Jacobs, 1996b; Jacques \& Reynald 2012; Johnson \& Natarajan 1995; VanNostrand \& Tewksbury, 1999). This prevents a felony charge if caught. Street dealers often have their stash 
innocuously hidden within sight, for example in an empty bottle, drain pipe, crumpled newspaper, or bush (Jacobs, 1996b; Jacobs \& Miller, 1998).

Dealers may also protect themselves from arrest by using a transactional medium for drugs sales (Fader, 2016; Jacobs, 1996b; Johnson \& Natarajan, 1995). This tactic involves hiding small amounts of drugs in various places so after receiving the money, the dealer can tell the buyer to go pick up a strategically placed newspaper or bottle across the street. The drugs are hidden from the public and prevent the dealer from making a hand-to-hand sale. Some dealers put more distance between themselves and the transaction by using a middle man or runner to accept the money and/or handoff the drugs (Fader, 2016; Jacobs, 1996b; Johnson \& Natarajan, 1995). If picked up by police, these dealers have neither cash nor drugs on their person and thus cannot be detained. These arrest avoidance tactics are useful in outdoor markets in urban settings. No research examines how rural drug dealers avoid detection during drug sales.

Few studies have examined the gendered avoidance strategies specifically used by women drug dealers (Jacobs \& Miller, 1998; Jenkot, 2008; Molloney et al., 2015). Women often exploited law enforcement officers' gendered assumptions that they were just hanging around the men for attention and were not selling or operating as a dealer. (Jacobs \& Miller, 1998; Jenkot, 2008; Molloney et al., 2015). Women dealers reduce detection by focusing on fitting in to their surrounding and using gender. For example, women discussed dressing casually and/or femininely and not wearing flashy clothes or jewelry to remain unnoticed by police. Women also incorporated selling into their daily routine activities and staging a normal looking situation, such as running errands with a baby or meeting a friend for lunch to conceal the fact that they are actually selling crack (Jacobs \& Miller, 1998; Molloney et al., 2015). While most drug market research explores men dealers, women develop their own unique strategies. However, the strategies uncovered in the research only explore how women in urban markets avoid police detection. Rural markets remain unknown.

Lookouts are a common law enforcement avoidance strategy (Johnson \& Natarajan, 1995; Molloney et al., 2015). Lookouts alert sellers to any police or other suspicious surroundings so dealers can avoid a sale that may result in their arrest. Sellers and buyers also talk to each other about neighborhood happenings. Sharing gossip alerts others to potential threats and helps them all avoid police detection. For example, buyers and sellers warn each other about people who are known to be dangerous or about someone who is acting careless, weird, or drawing police attention (Dickinson \& Wright, 2015; Jacques \& Allen, 2014; Johnson \& Natarajan, 1995). Dealers avoid selling to such buyers and buyers can seek out safer sellers. Dealers also talk to each other about customers. Information about who was recently arrested can alert dealers to buyers and suppliers who may now be reporting back to police (Dickinson \& Wright, 2015). By sharing information about suspicious or recently arrested individuals, buyers and sellers can potentially avoid participating in a sale that may lead to their arrest. The extent to which dealers in rural markets discuss informants and arrested buyers is unknown. 
Women structure their business differently than men. Women reported being particularly nice to neighbors, for example giving them food, inviting them over for BBQs, or making polite conversation, to build rapport and decrease the likelihood of neighbors alerting police to any suspicious activity. Women were even making drug deals during those same BBQs that presented them as good neighbors (Jacobs \& Miller, 1998). Women also avoid detection by limiting their selling hours (Jacobs \& Miller, 1998; Morgan \& Joe, 1996). Jacobs and Miller (1998) found that women essentially hold standard business hours and do not make sales after the liquor store or bars close because open businesses give dealers a legitimate excuse for walking around outside if questioned by police. Similarly, in their study of mostly white, mostly male 18-23-year-old suburban drug sellers, Jacques and Allen (2014) found that dealers would limit their business hours to prevent their parents from finding out that they were selling drugs. The dealers would limit their sales to the window of time after school let out but before their parents arrived home from work. It is unknown what are considered acceptable or suspicious hours of operation for drug dealers in rural communities.

Limited research examines the strategies dealers use to avoid detection while driving (Jacobs 1993; Jacobs, 1996a; Dickinson \& Wright, 2015). When dealing with buyers, certain vehicle characteristics clue sellers in to the fact that the buyer is likely an undercover officer. Jacobs (1993) found that dealers avoided selling to buyers who drove up in nice, clean cars. Dealers understand drug users span socioeconomic status, but 'beater' cars filled with trash and food wrappers lend authenticity to the buyer (Jacobs, 1996a). Unmarked police vehicles often have attributes that tip off dealers to avoid the sale. These attributes include cars and vans with four doors (easy for police to jump out), tinted windows, radio antennae, missing plates or registration stickers, and electronics attached to the dashboard (Jacobs, 1996a). Conversely, when dealers are driving, they wear their seatbelt, follow traffic laws, and have minimal passengers (Dickinson \& Wright, 2015). Dealers have several vehicle related tactics for avoiding law enforcement depending on whether the potential buyer is driving up to a sale or if the seller is travelling with drugs. It is unknown if these same sting operation threats exist for rural markets, or what unique vehicle issues and strategies exist.

Drug dealers paid close attention to physical cues of buyers to avoid selling drugs to undercover officers (Jacobs, 1993; Jacobs, 1996a; Johnson \& Natarajan, 1995; Molloney et al., 2015). When assessing buyers, dealers are accustomed to seeing addicts who had an "emaciated, unkempt, and otherwise filthy appearance, spending all of their money on crack at the expense of nutrition and personal hygiene" (Jacobs, 1996a:417). Crack addicts also have visible signs of addiction, including lip sores and blisters from smoking, pockmarks on their faces, and black lighter marks on their hands (Jacobs, 1996a). Conversely, undercover officers also have distinctive tells. The main tell, dealers reported, are their clothes (Jacobs, 1993; Johnson \& Natarajan, 1995). Dealers find undercover officers have a sort of undercover uniform and look alike when conducting sting operations (Jacobs, 1993). In addition to wearing the wrong clothes, undercover offices wear clothes that are clean and fit their bodies well (Jacobs, 1993; Johnson \& Natarajan, 1995). Drug users dress sloppy so a shiny belt or clean sneakers can give away an 
undercover officer. Undercover officers also carry themselves differently from drug users (Jacobs, 1993; Johnson \& Natarajan, 1995). They are often muscular and carry themselves in a confident, assertive fashion from military style training drills (Jacobs, 1993; Johnson \& Natarajan, 1995). Dealers in Jacobs' (1993) study divulged that undercover officers' eyes were too full of life to convincingly pass as a crack user. These studies almost exclusively focus on crack and heroin markets. It is unknown what physical cues, if any, dealers or cooks use to determine undercover law enforcement in rural or methamphetamine markets.

Drug dealers also identify undercover officers through verbal cues (Jacobs, 1993; Jacobs, 1996a; Jacques \& Reynald, 2012; Johnson \& Natarajan, 1995). When making a buy, dealers report that undercover officers are too pushy about making a transaction happen (Jacobs, 1993; 1996a). Undercover officers present differently than crack users in that they are not nervous about getting busted by police, they do not negotiate over the price, strike up conversation, and always pay with crisp twenty-dollar bills (Jacobs, 1993; 1996a). Drug dealers have a set lingo that serves as a secret code with their buyers (Jacques \& Reynald, 2012) and undercover officers are often out of touch with the current lingo or are unaware of the routine exchange of words that regular buyers know (Jacques \& Reynald, 2012; Johnson \& Natarajan, 1995). The ability to identify undercover officers is a useful avoidance strategy because dealers can not only refuse a sale and avoid arrest but stash their drugs and money to prevent officers from finding anything if the situation is escalated to a frisk or search.

The research examining restrictive deterrence and detection avoidance strategies detailed above focuses on urban areas and predominately crack cocaine markets (Jacobs \& Miller, 1998; Jacobs, 1996a; 1996b; Johnson \& Natarajan, 1995; Molloney et al., 2015; VanNostrand \& Tewksbury, 1999). A few reviewed studies examine avoidance tactics in marijuana markets (Bouchard \& Nguyen, 2010; Fader, 2016; Molloney et al., 2015), heroin markets (Jacobs, 1993), mixed markets excluding methamphetamine (Fader, 2016; Jacques \& Reynald, 2012), or mixed markets with only one participant selling methamphetamine (Dickinson \& Wright, 2015). Only Jenkot (2008) and Morgan and Joe (1996) examine methamphetamine markets but neither study specifically examines arrest avoidance strategies. This study seeks to explore restrictive deterrence in methamphetamine markets that operate in rural communities.

\section{Rural spaces}

Rural areas experience disproportionately increasing rates of drug use, particularly opioids and methamphetamine (Dombrowski et al., 2016; Garriott, 2011). According to the Centers for Disease Control and Prevention (2018), usage rates for opioids are quite similar across rural, urban, and metropolitan areas, while methamphetamine use is greatest in rural communities. In their survey of Nebraskans, Habecker et al. (2018) found that compared to urban users, rural drug users began using drugs at an earlier age and were more likely to use and sell methamphetamine. Rural methamphetamine users also used riskier methods; up to one-half of rural Nebraska methamphetamine users preferred injection-based use, a rate that is twice that of 
urban methamphetamine users (Grant et al., 2007; Habecker et al., 2018). In their study of nearly 19,000 adolescents from communities of less than 50,000, Rhew et al. (2011) found that middle and high schoolers living on a farm in rural communities had the highest use rates of alcohol, cigarette, marijuana, smokeless tobacco, inhalant, and other illicit drugs, followed by middle and high schoolers living in rural communities but not on a farm, and those who live in a town, respectively.

Rural law enforcement officers see the devastating toll drugs take on the community (Donnermeyer et al., 2011; Hafley \& Tewksbury, 1996; Linneman \& Kurtz, 2014). In their study involving interviews with Kansas officers and hours of ride alongs, Linneman and Kurtz (2014) found that officers in both urban and rural areas viewed burglary and drugs as the biggest threat to their communities. However, the types of drugs causing the problems varied; urban officers named a variety of drugs while rural officers only identified methamphetamine (Linneman \& Kurtz, 2014).

Not only are drugs, specifically methamphetamine, used in rural areas and problematic for law enforcement, residents report that drugs are easily accessible (Habecker et al., 2018). Thirtyfive percent of adult Nebraskans knew at least one person from whom they could obtain marijuana, nearly twenty percent for prescription pills, and nine percent for methamphetamine, regardless of urban or rural status (Habecker et al., 2018).

Despite the prevalence in drug use and access, rural policing can be quite different from non-rural areas. Culture, communities, lifestyles, and unique crimes make rural policing styles distinctive when compared to policing styles in urban jurisdictions (Cebulak, 2004; Donnermeyer \& Barclay, 2005; Donnermeyer et al., 2011; Weisheit et al., 1994). Many rural agencies are also chronically underfunded and understaffed (Weisheit, 1993). This often manifests in minimal training, outdated equipment, fewer colleagues, and older technology (Christensen \& Crank, 2001; Oliver \& Meier, 2009; Scott, 2004; Weisheit et al., 995). Rural law enforcement agencies do not have divisions of specializations that are typical of larger cities, thus rural officers are viewed as generalists (Maguire et al., 1991; Payne et al., 1998). Rural law enforcement officers are often called to deal with personal problems that are outside of their traditional scope. A study of a small town in Pennsylvania found that police were used as animal control, code enforcement, and arbiters of community dysfunction (Payne et al., 2005). Arrest rates rarely reflect the high rates of rural use because drug arrests tend to be proactive in nature (Castellano \& Uchida, 1993). Therefore, arrest rates reflect the difference in rural law enforcement efforts and staffing rather than actual consumption rates (Castellano \& Uchida, 1993).

This study furthers the theoretical understanding of restrictive deterrence and rural policing by examining arrest avoidance strategies used by 52 men and women in rural methamphetamine markets around Michigan. This study examines two questions. First, what do arrest avoidance 
strategies in rural methamphetamine markets look like? And second, if arrested, how do drug market involved individuals explain their arrests?

\section{Methodology}

\section{Local context}

Participants lived in various Michigan counties and were involved in methamphetamine related activities in the past two years. Participants were concentrated in less populated areas of the state, including the southwest, southcentral, and northwestern regions (see Figure 1). Participants were not asked about the communities in which they lived. Some referenced living in areas that would be defined as rural by the U.S. Census Bureau (Ratcliffe et al., 2016) in that they lived in small towns with less than a few thousand people. Others referenced living in the larger cities where we met for the interviews. Despite being from a variety of communities, participants sought out rural spaces to engage in methamphetamine production and sales.

Sixty percent of participants discussed arrest avoidance strategies using words synonymous with rural spaces. The most common reference to rural communities was being out in the country. For example, Chelsea (a pseudonym) states "We were very careful about where we did it. It was mostly out in the country." Jeremy reiterates "Out in country everything was pretty isolated." Participants also used woods (e.g. "In woods- go way out where no one would see"), cornfields (e.g. "I always cooked in cornfields."), or rivers and streams (e.g. "[had] some favorite spots, beaches, riversides were nice. Anything with water around.") to covertly manufacture methamphetamine or hide supplies. Participants also made a point to mention avoiding town. For example, Chelsea reiterates "Not in town, that's for sure. Wherever was deserted and not a lot of traffic, not a lot of cops, basically not in town. Or if so, out of city limits." Further, participants describe their routes in terms of back roads or dirt roads. Lastly, participants talk a great deal about burning trash. While burning trash and firepits are not strictly rural concepts, participants do need a certain amount of privacy to burn methamphetamine laboratory components. Also, some participants refer to these fires as bonfires, which alludes to a larger fire in a more remote area. Through this language, it is clear that avoiding arrest for methamphetamine related charges is inextricably linked to rural spaces and communities.

\section{Sampling and recruitment}

The sample consisted of Michigan residents with current or former experience manufacturing, selling, using, or obtaining ingredients for manufacturing methamphetamine. Purposive sampling strategies were used to recruit participants who were at least 18 years of age and took part in some aspect of manufacturing, selling, or using methamphetamine within the past two years. 

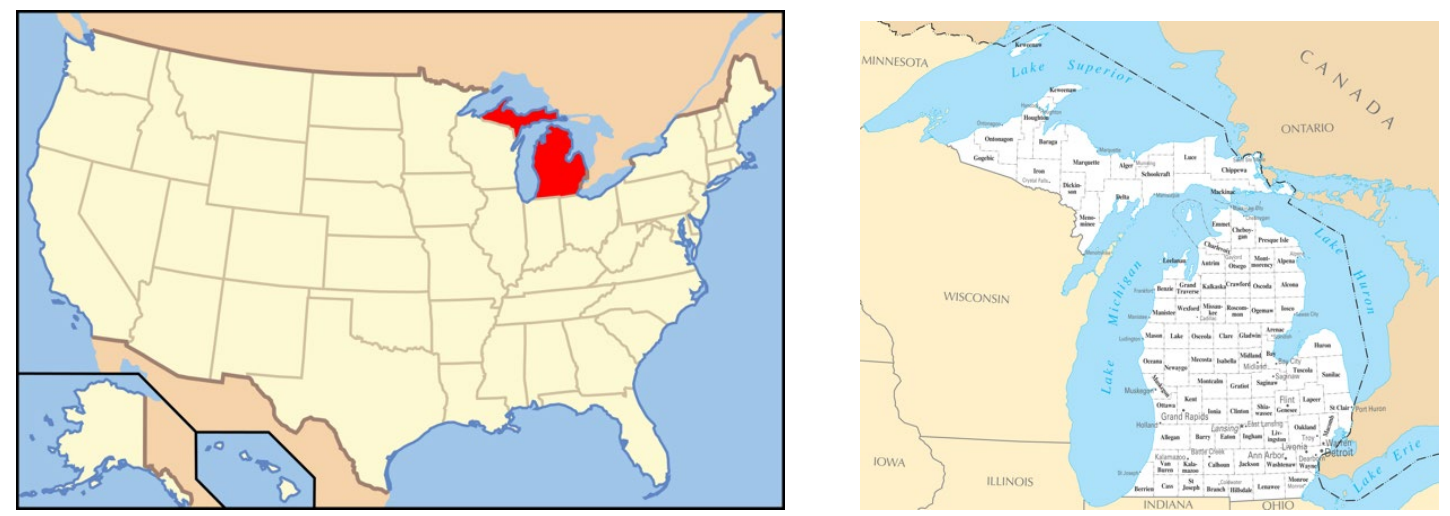

Figure 1: Location of Michigan and counties and cities within Michigan (https://commons.wikimedia.org/wiki/File:Map_of_USA_MI.svg)

Several strategies were used to recruit participants. First, several women known to the researcher from another study of women on probation or parole who had a history of methamphetamine offenses were contacted. Seven women were recruited to participate through their contact with previous studies. Second, flyers were distributed in strategic locations, particularly in southwest Michigan where rates of methamphetamine use and found laboratories were high (Drug Enforcement Agency, 2019). Flyers were disseminated in drug courts, Narcotics Anonymous, and Alcoholics Anonymous meeting spaces or with group leaders in five towns and cities. Seven participants, five men and two women, were recruited through disseminated flyers. Third, snowball sampling and theoretical sampling were used to recruit additional participants, particularly participants in underdeveloped methamphetamine market positions (e.g. women cooks) and with unique experiences (e.g. organized a Sudafed buying system with 50 'employees' and a driver for the cook). Snowball sampling led me to networks previously unknown, at least methamphetamine-related, to police as my sample quickly consisted of participants who were never arrested for methamphetamine related offenses. Ongoing analysis revealed my lack of data on those who were arrested, so I used snowball sampling to carry out theoretical sampling by asking participants if they knew anyone who was arrested for methamphetamine offenses. Eighteen women and twenty men were recruited through snowball and theoretical sampling. Each participant received a $\$ 50$ visa gift card for participation.

A total of 52 participants ( 25 men, 27 women) ranging in age from 18 to 60 participated in the study (see Table 1). Most participants were in the 31-35 years of age category. Ninety-five percent of the sample was white. Over half the sample had no more than a high school diploma. At the time of their interview, nine participants were on probation or parole (although none for methamphetamine related offenses) while eighteen were drug court participants. 


\begin{tabular}{|c|c|c|c|}
\hline \multicolumn{4}{|c|}{ Table 1: Participant characteristics } \\
\hline & Men & Women & Total \\
\hline \multicolumn{4}{|l|}{ Age } \\
\hline $18-25$ & $5(20 \%)$ & $5(19 \%)$ & $10(19 \%)$ \\
\hline $26-30$ & $2(8 \%)$ & $4(15 \%)$ & $6(11 \%)$ \\
\hline $31-35$ & $5(20 \%)$ & $8(30 \%)$ & $13(25 \%)$ \\
\hline $36-40$ & $4(16 \%)$ & $2(7 \%)$ & $6(12 \%)$ \\
\hline $41-50$ & $3(12 \%)$ & $5(19 \%)$ & $8(15 \%)$ \\
\hline $51-60$ & $6(24 \%)$ & $3(11 \%)$ & $9(17 \%)$ \\
\hline $61+$ & $0(0 \%)$ & $0(0 \%)$ & $0(0 \%)$ \\
\hline \multicolumn{4}{|l|}{ Race } \\
\hline White & $22(88 \%)$ & $27(100 \%)$ & $49(95 \%)$ \\
\hline Nonwhite & $3(12 \%)$ & $0(0 \%)$ & $3(6 \%)$ \\
\hline \multicolumn{4}{|l|}{ Education } \\
\hline Less than high school & $2(8 \%)$ & $7(26 \%)$ & $9(17 \%)$ \\
\hline GED & $9(36 \%)$ & $4(15 \%)$ & $13(25 \%)$ \\
\hline High school diploma & $5(20 \%)$ & $8(30 \%)$ & $13(25 \%)$ \\
\hline Some college & $6(24 \%)$ & $6(22 \%)$ & $12(23 \%)$ \\
\hline College degree & $3(12 \%)$ & $1(4 \%)$ & $4(8 \%)$ \\
\hline More than college & $0(0 \%)$ & $1(4 \%)$ & $1(2 \%)$ \\
\hline
\end{tabular}

\section{Interviews}

In-depth interviews consisted of open-ended questions posed in a loosely structured format. Participants were asked about the various strategies they used to avoid police detection in their various roles surrounding methamphetamine production. I sat next to each participant and typed the responses word-for-word during the interview. Participants were able to follow along and see that I was not documenting names of those they mentioned and correct anything I recorded incorrectly, thus increasing validity. No participants wanted a copy of their transcript. Interviews were conducted between December 2012 and April 2013. Interviews occurred at public libraries, 
restaurants, coffee shops, and other public locations that were public but had some degree of privacy available and had an available wireless internet connection. Because I was also interviewing law enforcement for a different part of this research project, law enforcement agencies across the state knew of my research. My institutional IRB and I were nervous about data being seized in the field. To ensure I never had data on me while traveling, and my university created a folder on a private server. After each interview I logged into the server from the interview site, uploaded my interview transcript, and deleted the interview document from my laptop. This ensured I never travelled with notes on my person in case of police intervention. Once I returned to my campus office I retrieved the transcribed interviews from the server and saved them on a password-protected computer in a locked office. Interviews lasted 45 to 150 minutes. Interviews were conducted until saturation was achieved.

\section{Confidentiality}

Law enforcement, including those in anti-methamphetamine task forces, were aware of my research project. A great deal of information divulged to me in interviews was previously unknown to police and many of the participants were never arrested for methamphetamine offenses. As mentioned above, I took care to never travel with data and did not audiorecord the interviews. To prevent my data from being subpoenaed I obtained a certificate of confidentiality (COC) through the National Institute of Health. With this certificate, I could not be forced to identify participants or hand over interview data, even by court subpoena, in a federal, state, or civil proceeding. This protected my participants from any law enforcement seizure of subpoena of my data. I received approval to waive signatures on the consent form so there was no record of participant names. I showed each participant the COC and explained its meaning. This diminished many participant's concerns about privacy and confidentiality. Assuring participants

of the COC legal protections, having the waiver of signatures on the consent form, and watching me type their responses without names or identifiers relieved fear and concern. Additionally, all participants were given pseudonyms.

\section{Analysis}

Interviews were uploaded into NVIVO, a qualitative software package. A grounded theory approach was used. While the importance of rural spaces was not specifically asked to participants, their answers overwhelmingly indicated that methamphetamine production and sales relied on sparsely populated areas out in the country. The data were coded for themes in restrictive deterrence and arrest avoidance strategies. Themes were combined through the open and axial coding stages. Men's and women's interviews were coded and analyzed together and compared in the analysis. I created a codebook during the coding process that a qualitatively trained colleague used to code ten random cases (nearly twenty percent of the data). The codebook was adjusted, and the process repeated until inter-coder reliability was established with a Cohen's Kappa of .95 (Miles \& Huberman, 1994). 


\section{Results}

Participants reveal many strategies to avoid detection by law enforcement. These strategies fall under the following methamphetamine related categories: obtaining ingredients, cooking, selling, transporting it in a vehicle, and while interacting with police. Participants report using anywhere from zero to 16 specific strategies across categories to avoid law enforcement $(\mathrm{n}=52$, $x=6.0, s d=3.4)$. Men, on average, report using more strategies $(n=25, x=6.32, s d=3.8)$ than women $(n=27, x=5.7, s d=3.1)$. Two participants $(3.8 \%)$, one man and one woman, do not use any strategies to avoid law enforcement. David never used methamphetamine and simply drives his brother and dad, both cooks, to stores so they can get components. Abby is only involved as a helper. The findings conclude with a discussion of participants who have been arrested for methamphetamine related charges and whether they were using any restrictive deterrence strategies at the time, and their thoughts on why the arrest happened.

Researchers have established that men and women use different arrest avoidance strategies across drug markets (Jacobs, 1993; 1996a; Jacobs \& Miller, 1998; Jenkot, 2008; Johnson \& Natarajan, 1995; Morgan \& Joe, 1996; Sviridoff \& Hillsman, 1994; Worden et al., 1994). In the analysis, strategies were analyzed by sex and no differences were found. In this sample, men and women use similar strategies to avoid law enforcement detection. Because of this, the following results will not address sex differences because they did not exist.

\section{Obtaining ingredients}

The aspect of manufacturing where participants take the most precaution to avoid detection is in obtaining ingredients (components). Sixty-two percent of participants who report ever getting ingredients for a methamphetamine cook use restrictive deterrence strategies during that activity.

The most common arrest avoidance strategy while obtaining components is using other people to buy the highly regulated Sudafed boxes. These purchasers are called 'boxers.' Sixteen participants discuss using boxers so they do not have to register their name at the pharmacy for each purchase. Andrew, a cook, says: "There's nothing worse than a cook getting his own boxes, having your ID taken." Kristin, a cook in business with her father, reveals that once she started cooking, she stopped purchasing boxes. As cooks, neither she nor her father wanted their names on the registry: We would "use different gophers - we'd always use different people. You use the same people all the time you're screwed with the registry. We, me and dad, never bought the stuff." Participants firmly believe that paying other people to purchase the boxes is an effective way to remain undetected.

Smurfing is another arrest avoidance strategy participants use to obtain Sudafed boxes (Bovett, 2006; Department of Justice, 2009; Deutch, 2011; Nemes, 2010; Rigdon, 2012; VanderWaal et al., 2008; VanderWaal et al., 2013). Smurfing is when shoppers move from store 
to store, buying as many boxes of cold medicine as is allowed by law to avoid triggering the precursor laws (VanderWaal, et al., 2013). Nine individuals (three men and six women) discuss alternating stores and towns in which they purchase Sudafed. Because not all Sudafed registries were online (meaning synced across stores) at the time of the interviews, smurfing allows individuals to go over the three-boxes-per-month limit if they just shop around. Chelsea, a helper, talks about travelling to different cities to get boxes: I "went out of town to get boxes. Been to Kalamazoo; one time we even went to Detroit to get boxes." Living in a rural area complicates many participants' ability to obtain Sudafed because there are sometimes only one pharmacy, a small number of pharmacists, and pharmacy staff recognize customers. Hillary only worked as a boxer but explains how being recognized by pharmacists prompted her to change stores:

Just because it's obviously not for personal use and I don't need that much Sudafed. I think I knew in my head something wasn't right so I didn't want a pharmacist to ask me any questions. If I went in on a Tuesday and went back on a Thursday and the same pharmacist was working I didn't buy any. I went to a different store.

Hillary leaves her rural location for larger cities to buy Sudafed under the protection of anonymity that urban shopping offers. Because all methamphetamine components are legal to purchase, methamphetamine involved individuals use unique particularistic restrictive deterrence strategies to avoid raising the suspicions of pharmacists.

\section{Cooking}

Seventy-five percent of participants use restrictive deterrence strategies during the cooking process to prevent detection and apprehension by law enforcement. Fourteen men and thirteen women in the sample cook methamphetamine. All twenty-seven cooks use at least one arrest avoidance strategy while cooking, and a few participants who do not cook report using strategies (e.g. cleaning) while helping with the cooking process.

The most commonly reported restrictive deterrence strategy during the cooking process is trash removal. Over half of participants discuss clean-up as a crucial step in avoiding law enforcement detection. Popular ways to discard trash are to burn it, dump it in rivers, and/or disseminate it in separate dumpsters. Michelle, a boxer who occasionally sold methamphetamine stresses the importance of disposing of all Sudafed packaging:

There are UPC codes on boxes. You have to always get rid of box trash. As soon as you get them you pop them and get rid of the boxes. You were breaking down and taking them out of the box right away. The silver foil, when you pull that back it has UPC codes on it. And when you pop the box, on the inside of the box where the glue goes, there's a UPC code in there.

These UPC codes are linked to the individual who signed the registry, so appropriately destroying any piece that could link to the purchaser is crucial in protecting the purchaser, or boxers, from being tracked down by police from suspicious garbage. 
In addition to disposing of box packaging, participants stress the importance of dumping other pieces of trash. Kyle describes the different ways in which he would discard trash when he cooked:

I burned trash, dumped it, or have a bonfire. It'll burn down but it doesn't turn to ashes. I'd get rid of it eventually but it floats. I tried to throw all my components in a bag and dump it in the river and it floats.

Rural Michigan offers many forests, fields, dirt roads, lakes, and streams. Participants used these spaces to discretely dispose of trash. Bonnie also found the floating components to be troublesome when she would dispose of her cook trash, but reveals her solution:

If you're going to the lakes or the deep ends of the river we'd wrap it up in a bag, get the air out, and tie a brick around it. We'd put it in coolers and threw it in dumpsters of companies and businesses... We always wore gloves so there were no prints, not even on the bag.

In addition to 'drowning' trash in a water source, Bonnie is also careful to prevent fingerprints, another common practice. Regina, a helper, describes several practices that involve fingerprint avoidance at commercial dumpsters, and rural burn sites:

I'd clean up, get rid of the garbage. That's a process. You can't keep it in your house. You try to be a little conscious of what dumpster you're going to put in it or if you burn it, there are things they can find in it that shows you're making dope. You got to clean out your house. You have to know how to dispose of it without leaving a trail to you. We'd use a fire pit - if you burn your trash you have to sift through ashes and get all the pucks out. [What's a puck?] Plastic and fertilizer/ice packs - when that gets to a certain point of heat it looks just like a hockey puck... If you dumped things in dumpsters you'd have to wipe off all the bottles. It's hard to pull prints off bottles and the chemical reaction usually pulls them off. But just to be safe. Hoses, bottles, you'd wipe things down. You don't use full dumpsters because you don't want your trash on top... We'd give it to some of the people who would trade boxes for dope. We'd give them a little extra dope to get rid of some garbage.

Participants are creative in disposing of manufacturing trash in ways that prevent their detection. Except for finding half-filled dumpsters, participants relied on their rural surroundings to dump trash. Manufacturing methamphetamine produces a great deal of waste that is very distinct to law enforcement. Market members highly valued access to land where they could burn garbage without suspicion or interference. Additionally, participants valued access to lakes and rivers where they could dump garbage.

Another arrest avoidance strategy used during the manufacturing process is choosing a private cooking location. Methamphetamine manufacturing is predominantly found in rural locations (Herz, 2000; Wermuth, 2000). Most participants appreciate the cover that rural areas 
provide. A common tactic to avoid law enforcement is to take advantage of the rural environment and cook in secluded, private locations. Eighteen respondents reported using this strategy. Chelsea explains her cook's preference for private locations:

We were very careful about where we did it. It was mostly out in the country. Not in town, that's for sure. Wherever was deserted and not a lot of traffic, not a lot of cops, basically not in town. Or if so, out of city limits. Not in a hotel.

A few participants put additional effort into location scouting by watching possible sites for a few days prior to manufacturing. Bonnie adds:

Sometimes we'd watch the spot for three to four days to see who was in and out and how many people came to the cemetery. The cemetery was the easiest because you could have the eyes throughout the whole cemetery. You could see the road, you could see the entrance.

Participants stress the importance of cooking in private, secluded locations, synonymous with rural areas, to avoid law enforcement detection and apprehension.

Similarly, twelve participants frequently change their cooking locations. Constantly switching locations reduces the likelihood that cooks will be detected. Regina reports that she and her partner, the cook, would "try not to be in the same place twice." They would find new locations to cook each time in order to keep law enforcement from discovering their market. Another cook, Jade, admits: "I wouldn't stay at the same place too long. I was always moving around." Nearly a quarter of participants reveal moving around and changing cook locations was an important strategy in avoiding exposure to law enforcement. These participants made use of different fields, abandoned barns, and forests to rotate manufacturing locations. Because the restrictive deterrence literature predominately focuses on urban areas and crack cocaine markets (Jacobs \& Miller, 1998; Jacobs, 1996a; 1996b; Johnson \& Natarajan, 1995; Molloney et al., 2015; VanNostrand \& Tewksbury, 1999), strategies used by methamphetamine cooks to avoid law enforcement detection remained unknown prior to this study.

\section{Selling}

Methamphetamine cooks and dealers are the market members responsible for selling the product. They choose their customers very carefully. Sixty percent of individuals discuss using specific tactics while selling to prevent arrest. Similar to the broader drug market research on avoiding arrest, participants in this study avoid arrest by selling to customers they know (Jacobs, 1993; Jacobs, 1996a; Jacques \& Allen, 2014; Jacques \& Reynald, 2012; Johnson \& Natarajan, 1995; Morgan \& Joe, 1996; VanNostrand \& Tewksbury, 1999; Worden et al., 1994).

Over a quarter of participants revealed that they only sell to a few customers. As a dealer, Sean takes special care to protect himself against selling to undercover officers or untrustworthy users who may “snitch." He explains: "I didn't deal with a lot of people. I sold to the same people unless they really couldn't meet... To me that's how you get [caught], selling to someone 
you don't know." Kyle explains his system as a cook: "I sold to people I knew or through people I knew. You give it [to] the people you know, don't mention my name, don't say where you got it, and don't bring them here." Kyle is careful to only sell to users he knows or has a connection with and stresses that his customers never mention his name. Similar to drug dealers in crack and heroin markets, methamphetamine dealers worry that selling to unknown customers could be a set up by police (Fader, 2016; Jacobs, 1993; Jacques \& Allen, 2014; Jacques \& Reynald, 2012; VanNostrand \& Tewksbury, 1999).

Cooks and dealers also protect themselves by frequently changing their phone numbers (Fader, 2016; Jacobs \& Miller, 1998). Twelve participants admit feeling paranoid that their phones were tapped or that police could use them to track their location. However, none of the individuals who were arrested for methamphetamine related charges report their phones playing any role in the incident. Elyssa explains: "I'd change my phone number frequently. I was paranoid - I'd think my phone was tapped." Other participants divulge keeping multiple cell phones - one for family and friends and legitimate use and one, or more, specifically for their methamphetamine business. Blake explains: "I had multiple phones at one time. This number is for personal calls and personal stuff and a couple throw-a-ways for people trying to get a hold of me to tell me they had something I might want." Changing phones, changing numbers, and keeping separate phones for business and personal use are commonly used law enforcement avoidance tactics in drug markets, regardless of type of drug or market setting.

\section{Driving}

While some participants focus on cooking privately and only selling to people they know, nearly half of the participants avoid police by using strategies focused on their vehicles. Restrictive deterrence literature proves that dealers selling in urban environments are focused on identifying undercover police vehicles (Jacobs, 1993; 1996a; Dickinson \& Wright, 2015) rather than driving themselves to sales. Driving with methamphetamine is necessary when leaving cook sites (e.g. abandoned buildings, homes, barns, fields, woods). Vehicles can also serve as a mobile cook site where a driver navigates around country backroads while a cook manufactures methamphetamine in a one-pot procedure over the course of a few hours (Vanderwaal, et al., 2013). Further, buyers and sellers are rarely on the same block so dealers either drive the methamphetamine to the buyer or the buyer picks up the drugs and must drive home with the product in the vehicle. Thus, driving with methamphetamine is unavoidable in rural markets. Participants report changing vehicles, ensuring their vehicles are legal (e. g. proper registration tags and stickers), and hiding methamphetamine creatively in the vehicle.

Twelve participants routinely switched cars to prevent being followed or identified by police. Paul prevents police from identifying his vehicle by constantly buying new ones: "I change cars, always change cars. I had a new car every two to three months." Changing cars make cooks and dealers more inconspicuous to local authorities. John, Jr. explains: 'I'd take other people's cars. I'd get on Craig's List and trade my car for something else. I'd buy a new 
car every few months. I'd always have cars in different people's names." Blake would routinely trade methamphetamine for the use of user's vehicles:

I switched cars all the time. I'd use other users' cars, 'here's a quarter gram, I'm going to use your car for a few days.' It'd turn into a half gram. I'd always make sure their insurance and registration was up to date.

Generally, law enforcement can identify and do recognize vehicles belonging to known or suspected offenders. In rural communities with smaller populations, individual police officer's abilities to associate vehicles with specific people is greater than in more populated areas (Linneman \& Kurtz, 2014). Law enforcement officers also associate people and vehicles often seen with known offenders with the illicit activities of the known offender. Thus, a user would not want to drive her same vehicle to a known cook's house at the risk of law enforcement learning what her car looked like and raising the interest of police. Constantly switching vehicles ensured law enforcement were never able to recognize a person's vehicle or associate someone with a particular car.

Seven participants take special care to hide methamphetamine or components in their vehicle while driving in case they are stopped by law enforcement. After cooking a batch in the woods, Tyler describes how he got the methamphetamine home:

I put the bottle in the muffler. And even when I rode with that I tucked it up in the car and took the muffler off and put it up in there. I had a fireproof safe and I'd put it in that up in the car where it couldn't be found.

Janet is very creative in how she hides methamphetamine in her vehicle: "I'd be placing it under the hood, in the trunk, in a Tampax container and melt it back shut. Anything to keep from riding dirty." Lastly, while smurfing, Jessica is careful to dispose of the box packaging, but is also vigilant in hiding the numerous pills in her vehicle: "On my [Major Cities] trips I would buy a teddy bear with collar or bow, slit the neck and stuff the pills in the bear. You have to hide thirty boxes or three-hundred pills at a time." Participants put a great deal of effort into hiding methamphetamine in their vehicles or in items within their vehicles in preparation for encounters with law enforcement. Restrictive deterrence tactics involving vehicles are not seen in the literature due to studies focusing on urban drug markets where buyers and sellers rarely drive.

\section{Interacting with police}

Despite participants using a great variety of law enforcement avoidance strategies, only two participants describe strategies for managing interactions with police. Larry, a professional boxer, states: "Police don't really know anything unless you tell them." While he did not have any interactions with police, his sentiment is shared by Michelle, who reports lying to police:

Me and Jenna were pulled over. We were clean, but we lied to them. We were telling them 'no, we don't know those people' but we had just left them. We knew they were 
watching... [We were] just lying to police, denying things. Denying association with them, deny being around them.

Additionally, while seven individuals reveal their dislike for snitches, one female cook, when apprehended by police, readily admits to giving law enforcement the name of someone involved in a methamphetamine market that she did not like so she would not get charged.

Lastly, and previously unfound in literature on methamphetamine markets, is the divulgence of corrupt police protecting a cook. This was only mentioned by one participant. Blake reveals:

I knew some people that worked for the sheriff's department, kind of like an inside thing. There are some people involved in law enforcement that used it too. They gave me favors and looked the other way. That's part of the reason I didn't get caught. I'd get a call and they'd say 'Where are you at? Police are raiding a house over here.' Or if they were patrolling a certain road, I'd stay off those roads.

Participants believed that lying to police and denying involvement in the methamphetamine business would be beneficial because the police would be unaware of their drug involvement. However, when forced to talk to law enforcement, participants lied, denied everything, or gave up the name of a competitor to avoid getting charged. Restrictive deterrence literature shows that drug dealers will avoid sellers who have been busted or arrested for fear that they are now conducting undercover buys for law enforcement in both urban and suburban settings (Dickinson \& Wright, 2015; Jacques \& Allen, 2014). While this arrest avoidance strategy exists in all drug markets, this study is the first to find a participant who admits to giving law enforcement names to avoid arrest.

\section{Using}

Six participants reveal strategies to avoid law enforcement while using methamphetamine. Four participants explain that they always stay home while using methamphetamine. This reduces the likelihood of being detected by police or someone else reporting them to law enforcement. Ed admits: "When we used, we stayed home and under the radar." Christy, a user who married into a family cook operation, discloses:

I would just be myself. I was scared to death. I've never been to jail and never wanted to be. I think that helped me getting me away from it. I only used at [husband] Kyle's house. For the most part we would just stay there. We were both paranoid, we wouldn't go many places unless we had to. We would stay in the yard but we wouldn't go out unless we had to.

Remaining at home allowed participants to comfortably get high without worrying about being seen or arrested by police. 
One main effect of methamphetamine is increased wakefulness (National Institute on Drug Abuse, 2006; United States Drug Enforcement Administration, 2006; Winslow et al., 2007). While many participants mention being awake for days or even a week at a time, two participants make it a point to regularly sleep to stay sharp and avoid accidents. Chrissa admits: "I'd get sleep and not get fucking looped up and spun out. After five days you start to hallucinate, and things don't make sense. I would sleep, catch up on sleep, and eat." Barb adds:

I would stay up 'til about 5 or 6 am and go to bed, high or not. Maybe I only slept for a few hours or not at all. But from 4:30 am to about 11 am or noon I would sleep or rest every day. I didn't like the paranoid feeling that you got with the sleep deprivation. Most meth addicts will go and go until they fall over... Resting or sleeping every night gave me better judgment than someone who's been up.

Staying home kept the users' chance of police detection low as there was no one to witness the user's behavior suspiciously and alert law enforcement. As a stimulant, a methamphetamine high can last up to twelve hours. While binging, a user can stay awake for up to ten days (Buxton $\&$ Dove, 2008). Long periods of methamphetamine use without sleep can have profound negative effects on one's brain and behavior, manifesting in anxiety, confusion, extreme paranoia, violence, and psychosis (Buxton \& Dove, 2008). By making a point to regularly sleep while binging, Barb avoided the negative psychological effects that would cause alarming and/or illegal behavior that certainly increase the likelihood of law enforcement involvement.

Restrictive deterrence literature on drug markets excludes drug users. A few participants in rural Michigan communities disclosed using arrest avoidance strategies while using methamphetamine.

\section{Arrest}

Participants spoke in depth about strategies they use to avoid police as well as their own legal history with methamphetamine. Participants were candid about whether they were ever arrested for any methamphetamine related offenses about the circumstances surrounding the arrest. Sixty-two percent of participants experienced an arrest for methamphetamine related charges. Thirty-one percent of participants who were arrested, however, admit they were not using any strategies at that time. Two participants learned to implement arrest avoidance strategies from their arrest. Five participants told on others for reduced charges, revealing a situation where arrest avoidance strategies are rendered useless if someone else decides to cooperate with police. A few participants were arrested under unusual circumstances, essentially negating any strategies they may have been using: two were arrested after laboratories exploded and one participant was arrested after a routine traffic stop alerted police to her warrant.

Six cooks explain that despite using their usual arrest avoidance strategies prior to their arrest, they were still captured by police. Elyssa, a cook involved in a family market, describes acting innocent with police and using her sister's identity to prevent law enforcement from realizing she had absconded: "I tried giving them my sister's birthday. I was absconding and I was out of state. I tried acting as normal as possible. I acted like I was just riding along [in the 
car with her friend]." Jade, her sister, explains getting reported to police during her routine trips out into the woods to cook:

When I caught my meth case I was outside on the railroad tracks. We tried to stay away from streets and houses, we tried to stay secluded. Someone called on us. It was a stranger. He seen us walk through his backyard. He said we were siphoning gas.

As stated above, participants mentioned lying and denying involvement when they came into contact with police. A warrant is a unique situation that renders lying moot. Matt explains how he did his best to minimize his involvement in the methamphetamine market when he knew law enforcement was coming:

No, we was good, I used everything [all the strategies] we did. I knew it [police/arrest] was coming by then. We had already cleaned up the house. I got caught with a .1 gram or something.

Due to his care in cleaning the house, Matt's charge was far less severe than it could have been had police found a laboratory or an array of components. Some participants, despite their best effort to avoid law enforcement, are still apprehended.

Two cooks explain that their methamphetamine related arrests were necessary in teaching them how to appropriately avoid police. After her arrest, Ashley ceased carrying and delivering her own methamphetamine: "After my first arrest I went back to cooking the day I got out. I just stayed out of town and made everyone come to me." Her arrest taught her the necessary steps to avoid police. Emily explains: "Within two weeks of involvement I got pulled over and raided. I learned from that what strategies to use." As brand-new cooks in the methamphetamine world, Ashley and Emily were arrested rather quickly. It was not until after their arrests that they learned different ways to avoid law enforcement during the cooking process, how to disguise it in vehicles, and most importantly, to cease communication with casual contacts, a wellestablished arrest avoidance practice that spans drug markets (Jacobs, 1993; 1996a; Jacques \& Reynald, 2012; Johnson \& Natarajan, 1995; Morgan \& Joe, 1996; VanNostrand \& Tewksbury, 1999; Worden et al., 1994).

Five participants, four of whom are cooks, claim their law enforcement avoidance strategies were effective and that they were only arrested because of someone else snitching. Five men and women explain the unique situations that lead them to believe others gave police their names. Trevor, who used to cook with friends, explains:

I was using my regular strategies. [But] I was set up. In that situation, there were about ten people in trailer when they [police] got there. They sat everyone down, interviewed everyone separately one by one into a room. I escaped. I took off running because there were only two police officers there. I was a couple miles from my house that night. After I got away I was in contact with my girlfriend on the phone thinking I could get a ride. Shortly after I told her where I was at the police showed up and I got caught. That's why 
I think I got set up. I was initially arrested for a probation violation. The meth charge wasn't issued until nine months later. It [the components] was sent to the DEA office in Detroit for testing.

Jeremy describes how effective his arrest avoidance strategies were when employed:

My strategies worked for a really long time. My friend told the police, that's what caught me up. I wasn't trying to make a bunch, I wasn't trying to be the center of attention. I try to keep quiet, stay out of the way to do it as privately as I could. Unfortunately, it worked for a long time. I stayed smart about it, I tried to be as smart as I could doing it. It worked out 'til I was told on by a friend.

Sixteen percent of participants believed that their usual arrest avoidance strategies were effective until a formerly trusted friend, family member, or significant other snitches. Gallupe et al. (2011) found that using arrest avoidance strategies actually increased subsequent arrests for drug offenders because implementing those strategies often meant putting themselves in new situations where they had to learn new tactics. According to the drug offenders in this study, arrest avoidance strategies can be effective. Participants who had experienced methamphetamine arrests understood how police came to know about them, and it was often because they were snitched on, or some other unusual circumstance that arrest avoidance strategies cannot control.

\section{Conclusion}

The goal of this study was to examine the various ways in which rural methamphetamine market participants avoid law enforcement during the manufacturing, distribution, and consumption process. The findings show that over half of the participants described strategies used while buying or stealing ingredients used to make methamphetamine. Participants often take great care in staying at or under the monthly limit on drugs needed for manufacturing, such as Sudafed, or they engage in 'smurfing' ingredients from other stores and towns (VanderWaal, et al., 2013). Participants are also very careful during the cooking process; they clean up after each step and use private locations to prevent being seen or heard. According to the participants, these strategies are effective in preventing law enforcement from learning about their business. Another aspect of the methamphetamine business where participants take great care to avoid police is when selling the substance. The most common way to avoid law enforcement during this task is to only sell to a select few customers, often friends, who they can be sure are not undercover law enforcement officers (Jacobs, 1993; 1996a; Jacques \& Reynald, 2012; Johnson \& Natarajan, 1995; Morgan \& Joe, 1996; VanNostrand \& Tewksbury, 1999; Worden et al., 1994). None of the participants discussed users working as confidential informants with police to reduce potential legal punishments, however several reported being set up and arrested because others acted as informants to police. Participants also detail specific rules they use while driving with methamphetamine, such as hiding it within the vehicle or in normal objects in the vehicle. 


\section{Practical and applied implications}

These findings lend themselves to many policy implications. First, this study offers the first detailed account of how methamphetamine involved men and women are avoiding arrest. Using this information to train law enforcement will render anti-methamphetamine task forces more effective and increase law enforcement apprehension rates. Second, because individuals are leaving cities and traveling to rural areas to conceal these crimes, law enforcement may use these findings to advocate for more funding and/or more officers. Third, law enforcement agencies can use these findings to train officers to better combat methamphetamine related offenses. This study reveals how methamphetamine manufacturers and sellers avoid police during every step of the process, often exploiting rural communities to better prevent their arrest. Lastly, the exploitation of rural areas, particularly woods and water sources, is ironic given the state's moto of Pure Michigan (Pure Michigan, 2019). State resources may be needed to ensure the pristine water, forests, and beaches advertised are actually clean and safe for visitors.

\section{Theoretical implications}

This study advances our understanding of how methamphetamine involved people avoid arrest and how they use rural areas to their advantage. Secluded fields, barns, and woods are ideal for cooking and keeping the pungent smell undetected. Participants routinely exploit the Michigan wilderness to dispose of the large amounts of waste methamphetamine manufacturing produces. Cooks dump trash in the numerous water sources and in woods. Unexamined in the restrictive deterrence literature is how individuals manage methamphetamine in their vehicles while driving. Arrest avoidance strategies while driving mirror those of urban dealers. Rural methamphetamine manufacturers change vehicles like urban drug dealers change phone numbers (Fader, 2016; Jacobs \& Miller, 1998). Additionally, rural methamphetamine manufactures are creative in hiding the drugs in their vehicle while urban drug dealers creatively hide crack on their person (Jacobs, 1996b). Rurality, however, is not always an advantage to avoiding law enforcement. Rural communities act as a barrier to methamphetamine producers during the ingredient acquisition stage. While obtaining the ingredients to cook methamphetamine, individuals avoid the pharmacies and pharmacists in their small towns in favor of the anonymity

of cities or other communities. While the other arrest avoidance strategies exploit rural communities in methamphetamine involved participants' favor, rurality works against shoppers trying to work around Sudafed limits.

\section{Limitations}

It is unclear if arrest avoidance strategies, particularly cleaning, work. Because I did not visit any laboratories I cannot speak to cooks' definition of clean. It may be that cooks and helpers actually do clean but once addiction, sleep deprivation, paranoia, or hallucinations occur, users may lose the capacity for maintaining these strategies. This may be the point at which the users become careless and are arrested. Future research can examine this discrepancy. While I did interview many law enforcement officers, including anti-methamphetamine task force 
members, I could not ask about specific cases or participants due to confidentiality. Therefore, I could not validate if each participants' arrest avoidance strategies did work or failed to work because of their reported extraordinary situations.

This study adds rural and methamphetamine representation to the extensive arrest avoidance literature. It reveals the challenges methamphetamine manufacturers face in their unique drug market as well as the ways in which their rural communities can be exploited to prevent police detection and arrest. By retreating into the wilderness to cook and dispose of trash, methamphetamine manufacturers have a discrete way to hide the smell, dispose of evidence, and avoid law enforcement on patrol. 


\section{References}

Bouchard, M., \& Nguyen, H. (2010). Is it who you know, or how many that counts? Criminal networks and cost avoidance in a sample of young offenders. Justice Quarterly, 27, 130158. https://doi.org/10.1080/07418820802593386

Bourgois, P. (1996). In search of respect: Selling crack in El Barrio. Cambridge University Press.

Bovett, R. (2006). Meth Epidemic Solutions. North Dakota Law Review, 82, 1195-1215.

Buxton, J. A., \& Dove, N. A. (2008). The burden and management of crystal meth use. Canadian Medical Association Journal, 178(12), 1537-1539. https://doi.org/10.1503/cmaj.071234

Castellano, T. C., \& Uchida, C. D. (1990). Local drug enforcement, prosecutors and case attrition: Theoretical perspectives for the drug war. American Journal of Police, 9, 133162.

Cebulak, W. (2004). Why rural crime and justice really matter. Journal of Police and Criminal Psychology, 19, 71-81. https://doi.org/10.1007/BF02802576

Centers for Disease Control and Prevention. (2018). Annual surveillance report of drug-related risks and outcomes- United States. Surveillance Special Report. Centers for Disease Control and Prevention, U.S. Department of Health and Human Services. Published August 31, 2018. https://www.cdc.gov/drugoverdose/pdf/pubs/2018- cdc-drugsurveillance-report.pdf.

Christensen, W., \& Crank, J. P. (2001). Police work and culture in a nonurban setting: An ethnographic analysis. Police Quarterly, 4, 69-98. https://doi.org/10.1177/109861101129197752

Deutch, H. (2011). The methamphetamine summit: A process in collaboration and decision making: A guide for law enforcement, community policing advocates, and community stakeholders. Washingon, DC: US Department of Justice. Retrieved from http://cops.usdoj.gov/Publications/e041119351_2011meth-summit.pdf.

Dickinson, T., \& Wright, R. (2015). Gossip, decision-making and deterrence in drug markets. British Journal of Criminology. https://doi.org/10.1093/bjc/azv010

Dombrowski, K., Crawford, D., Khan, B., \& Tyler, K. (2016). Current rural drug use in the U.S. Midwest. Journal of Drug Abuse, 2(3), 1-8.

Donnermeyer, J. F., \& Barclay, E. (2005). The policing of farm crime. Police Practice and Research, 6, 3-17. https://doi.org/10.1080/15614260500046913 
Donnermeyer, J. F., DeKeseredy, W. S., \& Dragiewicz, M. (2011). Policing rural Canada and the United States. In R. I. Mawby \& R. Yarwood (Eds.), Rural policing and policing the rural (pp. 23-32). Ashgate.

Drug Enforcement Agency (2019). Drug labs in the United States: National Clandestine Laboratory register data. Retrieved from https:/www.dea.gov/clan-lab.

Fader, J. J. (2016). “Selling smarter, not harder”: Life course effects on drug sellers' risk perceptions and management. International Journal of Drug Policy, 36, 120-129. https://doi.org/10.1016/j.drugpo.2016.04.011

Gallupe, O., Bouchard,M., \& Caulkins, J. P. (2011). No change is a good change? Restrictive deterrence in illegal drug markets. Journal of Criminal Justice, 39, 81-89. https://doi.org/10.1016/j.jcrimjus.2010.12.002

Garriott, W. (2011). Policing methamphetamine. New York University Press.

Gibbs, J. P. (1975). Crime, punishment, and deterrence. Elsevier

Grant, K. M., Kelley, S. S., \& Agrawal, S. (2007). Methamphetamine use in rural Midwesterners. American Journal of Addiction, 16, 79-84. https://doi.org/10.1080/10550490601184159

Habecker, P., Welch-Lazoritz, M., \& Dombrowski, K. (2018). Rural and urban differences in Nebraskans' access to marijuana, methamphetamine, heroin, and prescription pills. Journal of Drug Issues, 48(4), 608-624. https://doi.org/10.1177/0022042618786717

Hafley, S., \& Tewksbury, R. (1996). Reefer madness in bluegrass country. Journal of Crime and Justice, 19, 75-94. https://doi.org/10.1080/0735648X.1996.9721530

Herz, D. C. (2000). Drugs in the Heartland: Methamphetamine Use in Rural Nebraska. National Institute of Justice. Retrieved from http://www.ncjrs.gov/pdffiles1/nij/180986.pdf.

Jacobs, B. (1993). Undercover deception clues: A case of restrictive deterrence. Criminology, 31(2), 281-299. https://doi.org/10.1111/j.1745-9125.1993.tb01131.x

Jacobs, B. A. (1996a). Crack dealers and restrictive deterrence: Identifying narcs. Criminology, 34(3),409-431. https://doi.org/10.1111/j.1745-9125.1996.tb01213.x

Jacobs, B. A. (1996b). Crack dealers' apprehension avoidance techniques: A case of restrictive deterrence. Justice Quarterly, 13(3), 359-381. https://doi.org/10.1080/07418829600093011

Jacobs, B. A., \& Miller, J. (1998). Crack dealing, gender, and arrest avoidance. Social Problems, 45(4), 550-569. https://doi.org/10.2307/3097212

Jacques, S., \& Allen, A. (2014). Bentham's sanction typology and restrictive deterrence: A study of young, suburban, middle-class drug dealers. Journal of Drug Issues, 44(2), 212-230. https://doi.org/10.1177/0022042613497936 
Jacques, S., \& Reynald, D. (2012). The offenders' perspective on prevention: Guarding against victimization and law enforcement. Journal of Research in Crime and Delinquency, 49, 269-294. https://doi.org/10.1177/0022427811408433

Jenkot, R. (2008). "Cooks are like gods": Hierarchies in methamphetamine-producing groups. Deviant Behavior, 29, 8, 667-689. https://doi.org/10.1080/01639620701876486

Johnson, B. D., \& Natarajan, M. (1995). Strategies to avoid arrest: Crack sellers' response to intensified policing. American Journal of Police, 14, 49-69. https://doi.org/10.1108/07358549510111947

Linnemann, T., \& Kurtz, D. L. (2004). Beyond the ghetto: Police power, methamphetamine and the rural war on drugs. Critical Criminology, 22, 339-355. https://doi.org/10.1007/s10612-013-9218-z

Maguire, B., Faulkner, W., \& Mathers, R. (1991). Rural police job functions. Police Studies, 14, 180-187.

Miles, M. B., \& Huberman, A. M. (1994). Qualitative data analysis: An expanded sourcebook (2nd Edition.). Sage.

Molloney, M., Hunt, G., \& Joe-Laidler, K. (2015). Drug sales, gender, and risk: Notions of risk from the perspective of gang-involved young adults. Substance Use \& Misuse, 50(6), 721-732. https://doi.org/10.3109/10826084.2015.978642

Molloney, M., Hunt, G., \& Joe-Laidler, K. (2015). Drug sales, gender, and risk: Notions of risk from the perspective of gang-involved young adults. Substance Use and Misuse 50(6), 721-732. https://doi.org/10.3109/10826084.2015.978642

Morgan, P., \& Joe, K. A. (1996). Citizens and outlaws: The private lives and public lifestyles of women in the illicit drug economy. Journal of Drug Issues, 26, 125-142. https://doi.org/10.1177/002204269602600108

National Institute on Drug Abuse. (2006). Methamphetamine. U. S. Department of Health and Human Services. Retrieved from http://www.nida.nih.gov/pdf/infofacts/Methamphetamine06.pdf.

Nemes, R. S. (2010). Shake and bake: The meth threat and the need to rethinking 21 U.S.C. Sec. 841(C)(2). Washington University Law Review, 88(993), 993-1020.

Oliver, W. M., \& Meier, C. (2009). Considering the efficacy of stress management education on smalltown and rural police. Applied Psychology in Criminal Justice, 5, 1-25.

Payne, B. K., Berg, B. L., \& Sun, I. Y. (2005). Policing in small town America: Dogs, drunks, disorder, and dysfunction. Journal of Criminal Justice, 33, 31-41. https://doi.org/10.1016/j.jcrimjus.2004.10.006 
Peak, K. J. (1998). Justice administration: Police, courts, and corrections management. Prentice Hall.

Pure Michigan. (2019). Welcome to Pure Michigan. Michigan Economic Development Corporation. Retrieved from https://www.michigan.org/.

Ratcliffe, M., Burd, C., Holder, K., \& Fields, A. (2016). Defining Rural at the U.S. Census Bureau. U.S. Census Bureau.

Rhew, I. C., Hawkins, D., \& Oesterle, S. (2011). Drug use and risk among youth in different rural contexts. Health Place, 17(3), 775-783. https://doi.org/10.1016/j.healthplace.2011.02.003

Rigdon, B. A. (2012). Pharmacists on the front lines in the fight against meth. Journal of Legal Medicine, 33(2), 253-283. https://doi.org/10.1080/01947648.2012.686815

Scott, Y. M. (2004). Stress among rural and smalltown patrol officers: A survey of Pennsylvania municipal agencies. Police Quarterly, 7, 237-261. https://doi.org/10.1177/1098611103258958

Sviridoff, M., \& Hillsman, S. T. (1994). Assessing the community effects of tactical narcotics teams. In D. L. MacKenzie \& C. D. Uchida (Eds.), Drugs and Crime (pp. 114-128). Sage.

US Drug Enforcement Administration. (2006). Methamphetamine. Retrieved from http://www.usdoj.gov/dea/concern/meth.html.

US Department of Justice. (2009). Pseudoephedrine smurfing fuels surge in large-scale methamphetamine production in California. National Drug Intelligence Center. Retrieved from www.oregondec.org/CSPSC/002a-NDIC-report.pdf.

VanderWaal, C., Bishop, R. M., McBride, D. C., Rosales, K., Chriqui, J. F., O’Connor, J. C., \& Terry-McElrath, Y. M. (2008). Controlling methamphetamine precursors: The view from the trenches. U.S. Department of Justice. https://doi.org/10.1037/e481452008-001

VanderWaal, C., Young, R., McBride, D., Chriqui, J., \& Terry-McElrath, Y. (2013). Smurfing in small toxic meth labs: Impact of state methamphetamine precursor policies. Journal of Policy Practice, 12(3), 231-255. https://doi.org/10.1080/15588742.2013.796214

VanNostrand, L., \& Tewksbury, R. (1999). The motives and mechanics of operating an illegal drug enterprise. Deviant Behavior, 20, 57-83. https://doi.org/10.1080/016396299266597

Weisheit, R. A. (1993). Studying drugs in rural areas: Notes from the field. Journal of Research in Crime and Delinquency, 30(2), 213-232. https://doi.org/10.1177/0022427893030002005

Weisheit, R. A., Falcone, D. N., \& Wells, L. E. (1994). Rural crime and rural policing (No. NCJ 150223). National Institute of Justice. 
Weisheit, R. A., Wells, L. E., \& Falcone, D. N. (1995). Crime and policing in rural and smalltown America: An overview of the issues. National Institute of Justice.

Wermuth, L. (2000). Methamphetamine use: Hazards and social influences. Journal of Drug Education, 30(4), 423-433. https://doi.org/10.2190/GMH7-3FWX-1AC1-RWXP

Winslow, B. T., Voorhees, K. I., \& Pehl, K. A. (2007). Methamphetamine Abuse. American Family Physician, 76(8), 1169-1174.

Worden, R. E., Bynum, T. S., \& Frank, J. (1994). Police crackdowns on drug abuse and trafficking. In D. L. MacKenzie \& C. D. Uchida (Eds.), Drugs and Crime (pp. 95-113). Sage. 